\title{
TRAPPC13 Is a Novel Target of Mesorhizobium amorphae Type III Secretion System Effector NopP
}

\author{
Dongying Liu, ${ }^{1}$ Yantao Luo, ${ }^{1}$ Xiaofeng Zheng, ${ }^{2}$ Xinye Wang, ${ }^{3}$ Minxia Chou, ${ }^{1, \dagger}$ and Gehong Wei ${ }^{1, \dagger}$ \\ ${ }^{1}$ State Key Laboratory of Crop Stress Biology in Arid Areas, Shaanxi Key Laboratory of Agricultural and Environmental \\ Microbiology, College of Life Sciences, Northwest A\&F University, Yangling, Shaanxi 712100, China \\ ${ }^{2}$ Shaanxi Hydrogeology Engineering Geology and Environmental Geology Survey Center, Shaanxi Institute of Geological \\ Survey, Xi'an, Shaanxi 710054, China \\ ${ }^{3}$ Moutai Institute, Renhuai, Guizhou 564500, China
}

Accepted 23 February 2021.

\begin{abstract}
Similar to pathogenic bacteria, rhizobia can inject effector proteins into host cells directly to promote infection via the type III secretion system (T3SS). Nodulation outer protein P (NopP), a specific T3SS effector of rhizobia, plays different roles in the establishment of multiple rhizobia-legume symbiotic systems. Mesorhizobium amorphae CCNWGS0123 (GS0123), which infects Robinia pseudoacacia specifically, secretes several T3SS effectors, including NopP. Here, we demonstrate that NopP is secreted through T3SS-I of GS0123 during the early stages of infection, and its deficiency decreases nodule nitrogenase activity of $R$. pseudoacacia nodules. A trafficking protein particle complex subunit 13-like protein (TRAPPC13) has been identified as a NopP target protein in $R$. pseudoacacia roots by screening a yeast two-hybrid library. The physical interaction between NopP and TRAPPC13 is verified by bimolecular fluorescence complementation and coimmunoprecipitation assays. In addition, subcellular localization analysis reveals that both NopP and its target, TRAPPC13, are colocalized on the plasma membrane. Compared with GS0123-inoculated $R$. pseudoacacia roots, some genes associated with cell wall remodeling and plant innate immunity down-regulated in $\Delta n o p P$-inoculated roots at $36 \mathrm{~h}$ postinoculation. The results suggest that NopP in $M$. amorphae CCNWGS0123 acts in multiple processes in $R$. pseudoacacia during the early stages of infection, and TRAPPC13 could participate in the process as a NopP target.
\end{abstract}

Keywords: nodulation outer protein $\mathrm{P}$, rhizobia, symbiosis, type III secretion system, trafficking protein particle complex subunit 13

${ }^{\dagger}$ Corresponding authors: G. Wei; weigehong@nwsuaf.edu.cn and M. Chou; minxia104@nwafu.edu.cn

Funding: This study was supported by the National Natural Science Foundation of China $(41830755,41977052)$, Key R\&D program of Shaanxi Province (2020ZDLNY07-09).

The RNA-seq data are available at National Center for Biotechnology Information Short Read Archive under Bioproject PRJNA644405.

*The $\boldsymbol{e}$-Xtra logo stands for "electronic extra" and indicates there are supplementary materials published online.

The author(s) declare no conflict of interest.

cc)(1) () () Copyright () 2021 The Author(s). This is an open access article distributed under the CC BY-NC-ND 4.0 International license.
Symbiotic interactions established between rhizobia and legumes represent a major nitrogen $\left(\mathrm{N}_{2}\right)$-fixing system that transforms atmospheric dinitrogen into ammonia. Since ammonia can be utilized directly by plants, the establishment of the symbiotic systems facilitates improvement in fertility and productivity of low-N soils and thereby, the enhancement of ecosystem functioning (Wagner 2011; Zahran 1999). In many cases, the formation of $\mathrm{N}_{2}$-fixing nodules on legume roots requires the cooperation of type III secretion system (T3SS) and Nod factor signalings (Janczarek et al. 2015; López-Baena et al. 2016). T3SS is used to deliver effector proteins from pathogenic bacteria to the cytoplasm of the host cells of many plants and animals to facilitate bacterial survival and promote infection (Jiménez-Guerrero et al. 2017). Many rhizobia, similar to pathogenic bacteria, interfere with signal transduction pathways and impair plant defense systems to establish symbiotic interactions with legumes through a functional T3SS (Miwa and Okazaki 2017; Robert-Seilaniantz et al. 2011). Many rhizobial T3SS effectors (T3Es) have been identified based on genetic, genomic, and proteomic approaches (Jiménez-Guerrero et al. 2017; Miwa and Okazaki 2017). For example, 87 T3Es belonging to 47 families were identified from Ensifer (Sinorhizobium) fredii and Bradyrhizobium japonicum using a genomic approach (Kimbrel et al. 2013). Some of the rhizobial T3Es show similarities with pathogenic T3Es such as NopT and NopM. In contrast, others T3Es, such as NopP, NopC, NopL, and NopI, are rhizobia-specific and have no detectable homologs in other bacteria (Ausmees et al. 2004; Miwa and Okazaki 2017).

As a widespread rhizobia-specific T3E, NopP participates in the establishment of multiple rhizobia-legume symbiotic systems. The inactivation of nopP in Sinorhizobium sp. strain NGR234 dramatically reduces the number of nodules formed on Flemingia congesta and Tephrosia vogelii (Skorpil et al. 2005); however, it has no effect on other legumes responsive to the T3SS of NGR234 (Kambara et al. 2009). In addition, infection of Vigna unguiculata with the nopP_NGR234 knockout mutant strain induces the formation of $36 \%$ more nodules than infection with the wild-type strain (Ausmees et al. 2004). The inactivation of nopP_HH103 facilitates symbiosis between $E$. fredii HH103 and Glycine max; yet, it is highly detrimental when T3SS-dependent secretion is blocked (López-Baena et al. $2008,2009)$. When the legume host is switched to $V$. unguiculata, mutation of nopP_HH103 has neutral effects on symbiosis, while mutation of nopL_HH103 increases nodule number and shoot biomass; however, mutation of both nopP_HH103 and nopL_HH103 impairs nodulation, causing decreases in nodule number and shoot biomass (Jiménez-Guerrero et al. 2017). In addition, NopL modulates signal transduction 
pathways, and nop $L$ expression prevents full induction of pathogenesis-related defense genes in Nicotiana tabacum (Bartsev et al. 2004). Although it has recently been reported that NopP directly interacts with GmNNL1 from Bradyrhizobium USDA110 in soybean (Zhang et al. 2021), the biological functions and targets of NopP in other legumes has not been fully elucidated.

Robinia pseudoacacia is a pioneer tree species exploited in ecological and vegetation restoration programs. Due to its rapid growth rate, high drought tolerance, and robust seed germination and $\mathrm{N}$ fixation capacity, $R$. pseudoacacia has high ecological importance and is planted extensively in the Loess Plateau of China (Boring and Swank 1984; Qiu et al. 2010). R. pseudoacacia plantations play a vital role in the improvement of soil properties and ecological restoration in this plateau region associated with severe soil erosion (Li et al. 2004). Previously, a rhizobial strain designated as Mesorhizobium amorphae CCNWGS0123 (GS0123) was isolated from the root nodules of $R$. pseudoacacia grown in heavy metal tailings (Hao et al. 2012) and its specific infection of $R$. pseudoacacia was verified by plant cross-nodulation tests (Chen et al. 2013). In strain GS0123, there are two T3SS gene clusters, T3SS-I and T3SS-II. T3SS-I, which is located in the symbiotic plasmid, is an integrated cluster containing all the basal components, while T3SS-II, which is located in the chromosome, lacks some of the structural genes of T3SSs. Plant assays have shown that T3SS-I is necessary for legume nodulation by strain GS0123, and the expression of T3SS-I structure genes can be up-regulated in the presence of flavonoids, in contrast to that in T3SS-II (Wang et al. 2019). However, the role of specific T3Es in the establishment of symbiosis between $R$. pseudoacacia and strain GS0123 is still unclear.

To explore the role of NopP in symbiosis establishment, we generated a nopP_GS0123 knockout mutant ( $\Delta$ nopP) and screened a yeast two-hybrid $(\mathrm{Y} 2 \mathrm{H})$ library from GS0123-inoculated roots of $R$. pseudoacacia to identify the direct target protein of NopP in host plant cells. Transcriptome analysis was used to identify candidate genes related to NopP function. The data presented in this study could enhance our understanding of the molecular mechanisms underpinning the establishment of rhizobia-legume symbiotic interactions.

\section{RESULTS}

NopP is an effector of T3SS of GS0123.

According to GS0123 genome sequencing data, the nopP gene with a tts box conserved element in the promoter region was identified on symbiotic plasmid. When strain GS0123 was cultured in tryptone-yeast extract (TY) broth, nopP_GS0123 could be induced by flavonoids, as detected by quantitative (q)PCR (Fig. 1A). It was speculated that NopP was a T3E of strain GS0123.

To determine whether NopP was secreted through T3SS-I in GS0123, supernatant of the wild-type strain and the T3SS-I and T3SS-II mutant strains induced with flavonoids was extracted and detected by mass spectrometry, respectively. NopP was detected in extracellular medium of the wild-type strain and the T3SS-II mutant strain but not in extracellular medium of the T3SS-I mutant strain (Supplementary Table S1), indicating that NopP was a T3E in GS0123.

Expression profiles of nopP_GS0123 in R. pseudoacacia.

During infection of $R$. pseudoacacia plants by strain GS0123, root-hair curling and infection threads (ITs) were detected at 4 days postinoculation (dpi) and the number of ITs peaked at $5 \mathrm{dpi}$. Root nodules emerged at approximately $10 \mathrm{dpi}$. The nodules did not mature fully until $18 \mathrm{dpi}$, and senescent nodules emerged after $30 \mathrm{dpi}$ (Chen et al. 2013; Wang et al. 2019). Based on these observations, the infection process can be divided into four phases: prophase of early stage ( 0 to $3 \mathrm{dpi}$ ), anaphase of early stage ( 3 to $7 \mathrm{dpi}$ ), middle stage ( 7 to $18 \mathrm{dpi}$ ), and late stage (18 to $30 \mathrm{dpi})$.

To analyze the changes in nopP_GS0123 expression during symbiosis establishment, we determined the relative expression of nopP_GS0123 in R. pseudoacacia roots inoculated with the wild-type strain (GS0123), based on qPCR (Fig. 1B). During

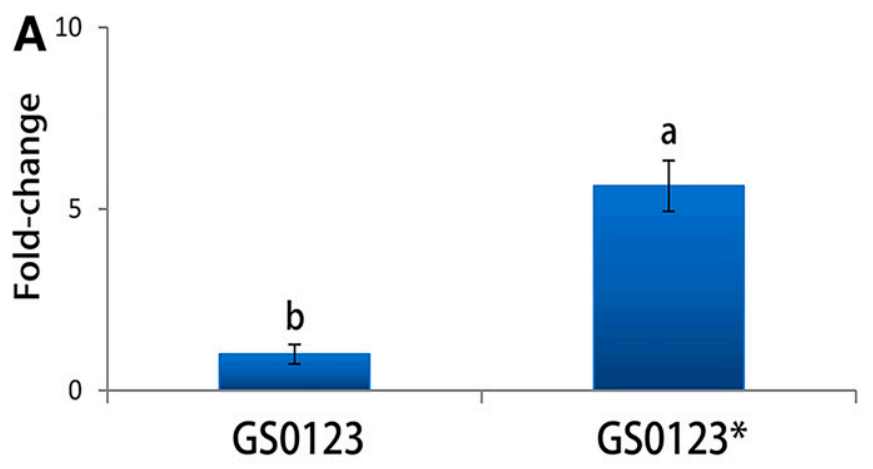
Sample name
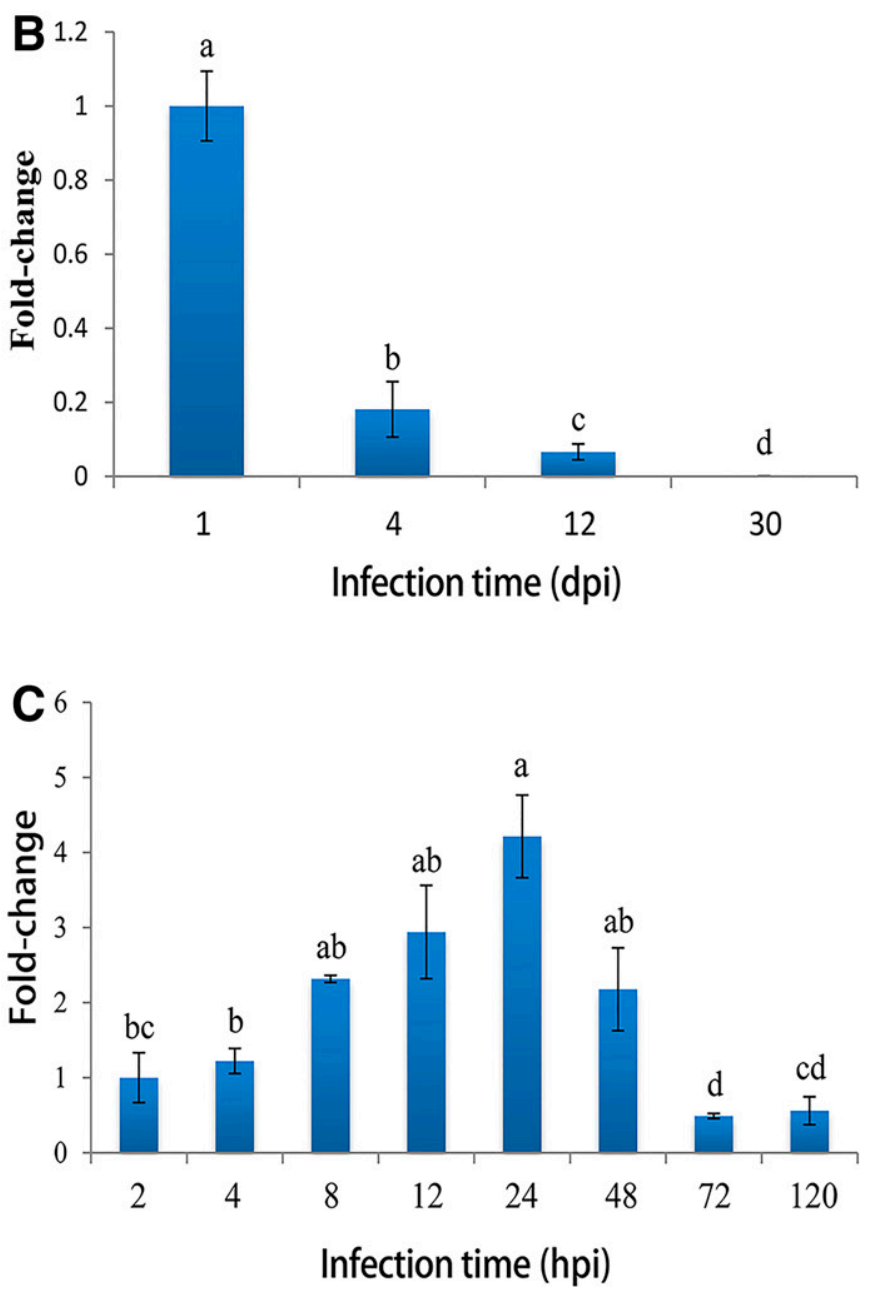

Fig. 1. Changes in the expression of nopP in Mesorhizobium amorphae CCNWGS0123 (GS0123). A, Relative expression level of nopP at $48 \mathrm{~h}$ after flavonoid induction in liquid culture (GS0123: without flavonoid induction, GS0123*: with flavonoid induction). The flavonoids used for induction were apigenin, luteolin, and naringenin; $\mathbf{B}$ and $\mathbf{C}$, Relative expression level of nopP during different stages of infection. Data shown are the mean \pm standard deviation of the mean for three biological replicates, the comparisons of means were performed using the natural $\log _{2}$-transformed data. Different letters above bars indicate significant differences (fold change value $\geq 2$ ). hpi $=$ hours postinoculation; dpi $=$ days postinoculation. 
different stages of infection, the highest relative expression of nopP_GS0123 was observed at $1 \mathrm{dpi}$, which decreased significantly with an increase in time of infection (4 to $30 \mathrm{dpi}$ ). Subsequently, gene expression over the first $120 \mathrm{~h}$ postinoculation (hpi) was measured, and the relative expression increased initially and peaked at $24 \mathrm{hpi}$ (Fig. 1C). NopP could play a role in symbiosis establishment during the prophase of early infection according to these initial results.

The trafficking protein particle complex subunit 13-like (TRAPPC13) protein is a novel interaction partner of NopP.

To determine the intracellular interactors of NopP, we screened a cDNA library prepared from GS0123-inoculated roots of $R$. pseudoacacia by a Y2H assay. From 20,000 candidates screened, 159 clones were sequenced and 24 unique clones were identified, of which TRAPPC13 was the only one with stable and strong fluorescence in the bimolecular fluorescence complementation (BiFC) experiments among the annotated potential targets. The full-length sequences of nopP and trappcl3 were inserted into pGBKT7 and pGADT7 vectors, respectively. According to the $\mathrm{Y} 2 \mathrm{H}$ assay results, NopP and TRAPPC13 expression had no toxic effects on yeast growth. Yeast carrying positive control plasmids pGADT7-T/pGBKT7-53 (encoding interacting gene products) turned blue on quadruple amino acid (-Leu/-Trp/-His/-Ade) dropout, aureobasidin A-positive (A), and $\mathrm{X}-\alpha$-Gal-positive $(\mathrm{X})$ plates $(\mathrm{QDO} / \mathrm{X} / \mathrm{A})$, while yeast carrying the negative control plasmids pGADT7-T/pGBKT7-Lam (encoding noninteracting gene products), pGBKT7-NopP, and pGADT7-TRAPPC13 did not grow. The results indicated that the bait NopP and the target TRAPPC13 could not autonomously activate the reporter genes; thus, they were suitable for screening the $\mathrm{Y} 2 \mathrm{H}$ library. The positive result was verified by yeast growth on QDO/X/A plates only when both pGBKT7-NopP and pGADT7-TRAPPC13 plasmids were expressed, which indicated a direct interaction between
NopP and TRAPPC13 (Fig. 2; Supplementary Fig. S1). To confirm the protein-protein interaction between NopP and TRAPPC13, we conducted BiFC and coimmunoprecipitation (Co-IP) assays in Nicotiana benthamiana leaves. Observations under a laser confocal scanning microscope revealed that NopP fused with the $\mathrm{C}$-terminal fragment of yellow fluorescent protein $\left(\mathrm{YFP}^{\mathrm{C}}\right)$ and TRAPPC13 fused with the N-terminal fragment of yellow fluorescent protein $\left(\mathrm{YFP}^{\mathrm{N}}\right)$, which jointly produced fluorescence on the plasma membrane (PM) in N. benthamiana leaves (Fig. 3). In addition, hemagglutinin (HA)-tagged TRAPPC13 was coexpressed in $N$. benthamiana leaves with Flag-tagged NopP, and the presence of NopP was detected by Western blotting with anti-Flag antibodies after incubation with anti-HA tag magnetic beads (Fig. 4). The results confirmed a strong interaction between NopP and TRAPPC13.

Subcellular localization of NopP and TRAPPC13 on the PM.

To examine the subcellular localization of NopP and TRAPPC13, N. benthamiana leaves were infiltrated with Agrobacterium tumefaciens GV3101 containing fusion proteins NopPeGFP (enhanced green fluorescent protein) and TRAPPC13-eGFP separately. Then, the fusion proteins were observed by laser confocal microscopy at 48 to $72 \mathrm{~h}$ postinfiltration. Green fluorescence was confined to the PM (Fig. 5), which indicated the accumulation of both NopP and TRAPPC13 on the PM. To confirm the result, NopP-eGFP and TRAPPC13-eGFP fusion proteins were coexpressed with the PM marker-mCherry fusion protein, which fluoresces red on the PM, in N. benthamiana leaves. An overlay of green fluorescence and red fluorescence in the infiltrated leaves indicated that NopP and TRAPPC13 were indeed localized on the PM (Fig. 5A and B). In view of the interaction between NopP and TRAPPC13, we constructed recombinant NopP-mCherry and TRAPPC13-eGFP vectors to determine whether TRAPPC13 was colocalized with NopP on the PM. The results showed that NopP

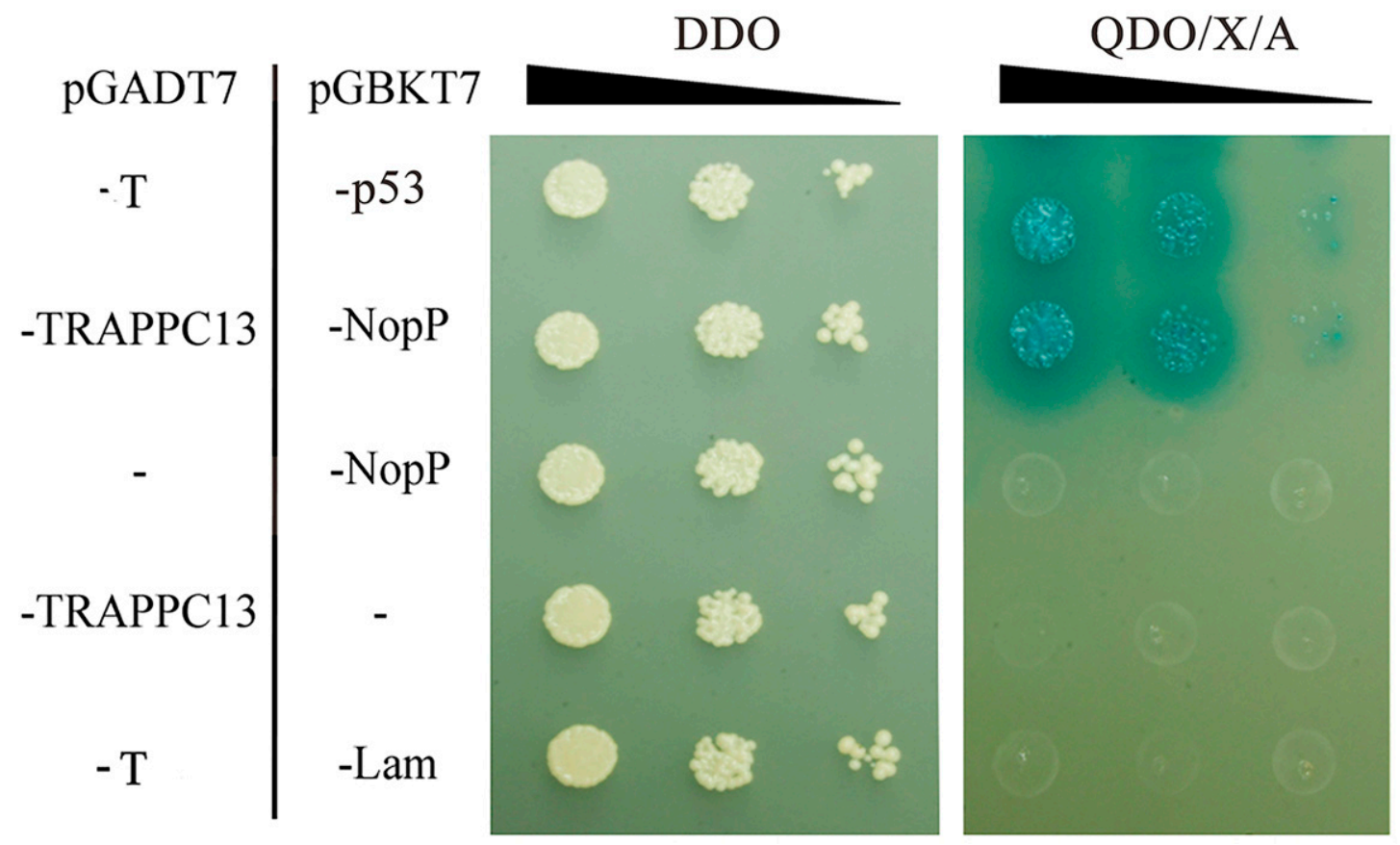

Fig. 2. Yeast two-hybrid assay of NopP-interacting targets in SD/DDO (synthetic defined/double amino-acid dropout) and SD/QDO/X/A (quadruple amino acid (-Leu/-Trp/-His/-Ade) dropout, aureobasidin A-positive and X- $\alpha$-Gal-positive) media. Yeast cells coexpressing the indicated combinations of constructs were grown on nonselective (DDO) or selective (QDO/X/A) plates. Yeast growth on the selective plates indicated protein-protein interaction. Full-length NopP and TRAPPC13 were inserted into pGBKT7 and pGADT7 vectors, respectively. Cotransformation of NopP and TRAPPC13 with empty carrier, respectively, showed that there was no self-activation. Cotransformation of pGBKT7-p53 and pGADT7-T antigen was used as positive control and that of pGBKT7-Lam and pGADT7T antigen was used as negative control. Ten-fold serially diluted cell cultures were inoculated on each spot as indicated by the triangle widths. A representative dataset of the experiment replicated three times on different biological samples was shown. 
potentially interacted with TRAPPC13 on the PM based on their colocalization (Fig. 5C). Both the confocal image and correlation plot profile represented the fluorescence from only eGFP, and mCherry vectors were ubiquitous in the nucleus, cytoplasm, and PM and cannot be merged (Fig. 5D).

The absence of NopP slightly affects symbiosis between $M$. amorpha CCNWGS0123 and $R$. pseudoacacia.

To explore the role of NopP in symbiosis establishment, root nodule traits and plant growth performance were compared between GS0123- and $\Delta$ nopP-inoculated $R$. pseudoacacia plants. Inoculation with $\Delta n o p P$ caused a slight but not significant increase in the nodule number and a minor decrease in the nodule biomass when compared with those in GS0123-inoculated plants (Fig. 6A and $\mathrm{B})$. In addition, there was a significant decrease in nodule nitrogenase activity in $\Delta n o p P$-inoculated roots at $30 \mathrm{hpi}$, and the change was offset by nopP compensation (Fig. 6C). There were no significant differences in plant height, root length, or plant biomass between treatments, while leaf chlorophyll concentrations decreased considerably in $\Delta n o p P$-inoculated plants as compared with that in the GS0123-inoculated plants (Supplementary Fig. S2). In addition, the root nodule volumes were lower in the $n o p P$-inoculated plants than in the GS0123-inoculated plants. However, microscopic observations of paraffin and ultrathin sections revealed no alterations in the internal structures of nodules or the morphological structures of bacteroids in the $\mathrm{N}_{2}$-fixation zone (Fig. 7).

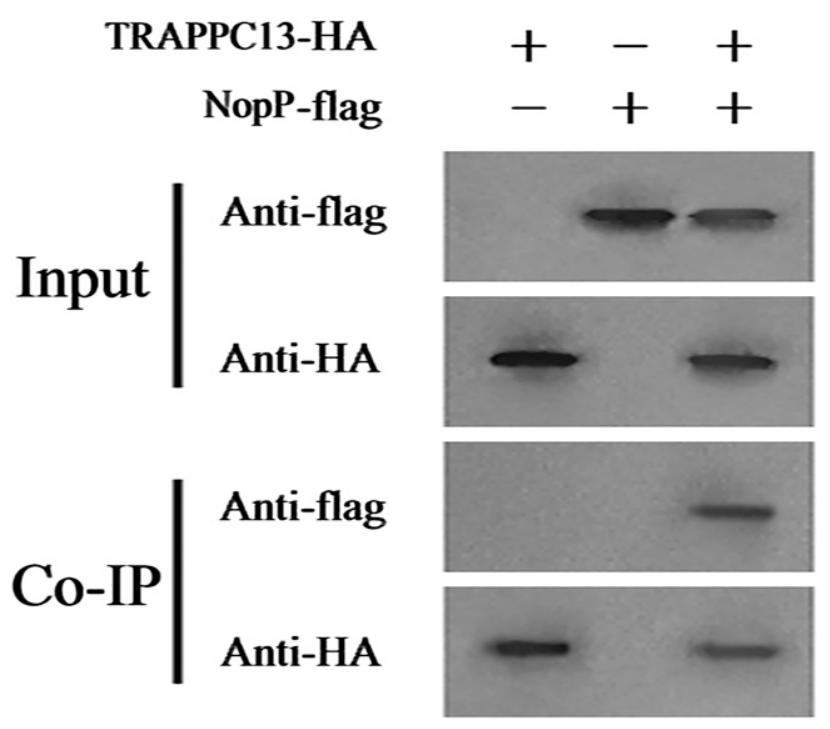

Fig. 4. Confirmation of protein-protein interaction between NopP and TRAPPC13 by coimmunoprecipitation (Co-IP) assay in Nicotiana benthamiana leaves. NopP was tagged with Flag epitope, while TRAPPC13 was tagged with hemagglutinin (HA) epitope. Proteins in the input and Co-IP samples were detected with antibodies against Flag and HA by Western blotting. NopP was pulled out by anti-HA-tag magnetic beads, indicating that it was immunoprecipitated by TRAPPC13.

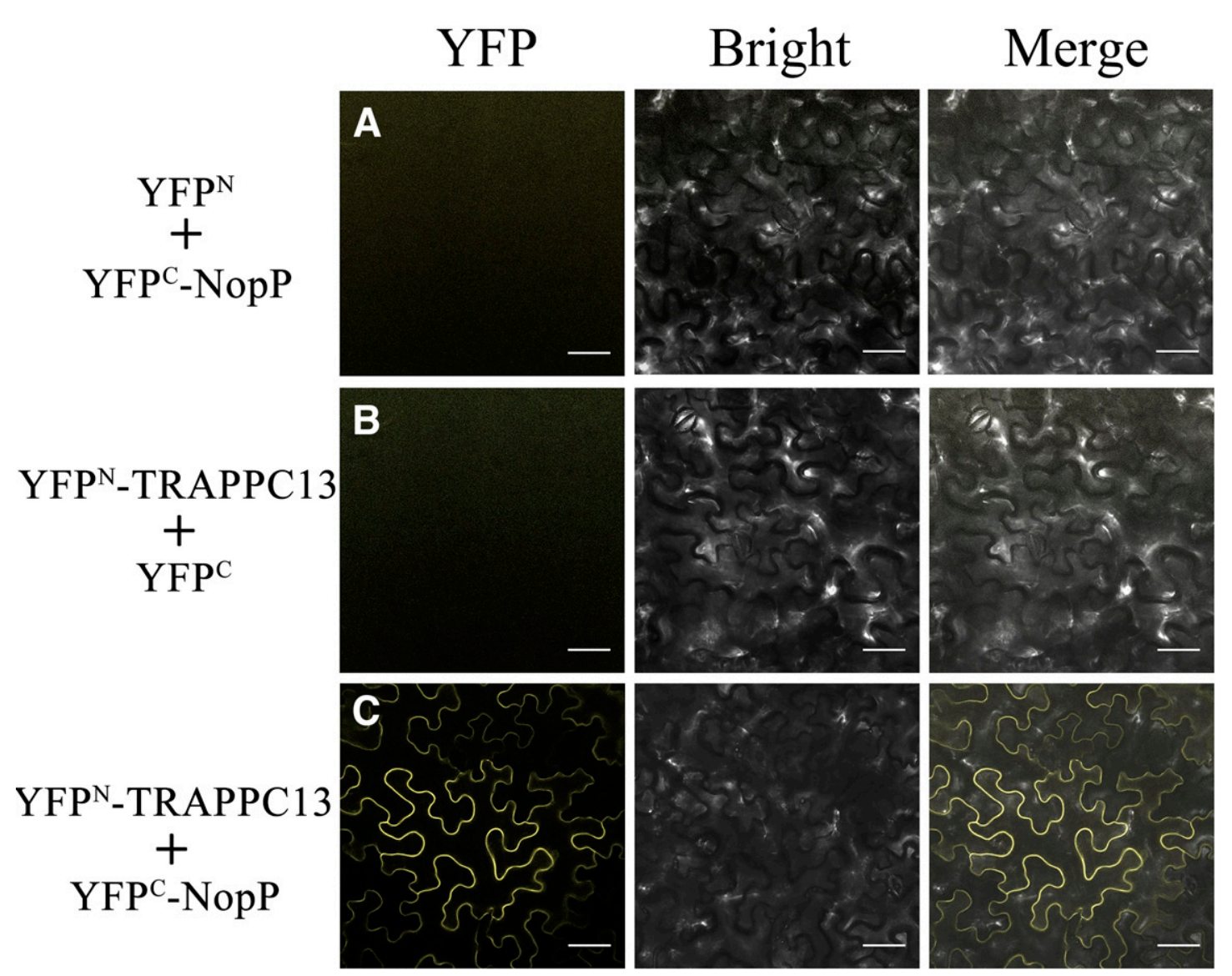

Fig. 3. Verification of protein-protein interaction between NopP and TRAPPC13 by bimolecular fluorescence complementation (BiFC) assay in Nicotiana benthamiana leaves. $\mathrm{A}, \mathrm{BiFC}$ assay between the $\mathrm{N}$-terminal half of yellow fluorescent protein $\left(\mathrm{YFP}^{\mathrm{N}}\right)$ and NopP fused to the C-terminal half of yellow fluorescent protein $\left(\mathrm{YFP}^{\mathrm{C}}-\mathrm{NopP}\right)$. B, BiFC assay between $\mathrm{YFP}^{\mathrm{C}}$ and TRAPPC13 fused to $\mathrm{YFP}^{\mathrm{N}}\left(\mathrm{YFP}^{\mathrm{N}}-\mathrm{TRAPPC} 13\right)$. C, BiFC assay between YFP $^{\mathrm{C}}-$ NopP and $\mathrm{YFP}^{\mathrm{N}}$-TRAPPC13. Reconstitution of yellow fluorescence indicated positive interaction on the plasma membrane (C) and the absence of fluorescence in negative controls (A and B). Scale bar $=50 \mu \mathrm{m}$. 
Gene expression responses of $R$. pseudoacacia to NopP during the prophase of early infection.

Two timepoints (36 and $72 \mathrm{hpi}$ ) were selected for transcriptome sequencing to study the gene expression responses of $R$. pseudoacacia to NopP during the prophase of early infection. Based on the RNA sequencing (RNA-seq) data, a relatively small number of genes were expressed in a specific manner, consistent with the substantial overlap between the genes expressed in GS0123- and $\Delta n o p P$-inoculated roots (Fig. 8A). Comparison of the genes expressed in $\triangle n o p P$-inoculated roots to those in GS0123-inoculated roots yielded 1,514 (321 upregulated and 1,193 downregulated) genes at $36 \mathrm{hpi}$ and 165 (93 upregulated and 72 downregulated) genes at $72 \mathrm{hpi}\left(\log _{2}\right.$ fold change $\geq 2, P<0.05$ ) (Fig. $8 \mathrm{C}$ and $\mathrm{D}$ ). Most of the differentially expressed genes (DEGs) showed significant differences in expression at one timepoint (Fig. 8B), suggesting a transcriptional reprogramming in response to $\Delta n o p P$ infection; however, many genes were expressed only transiently during the prophase of early infection. The RNA-seq data were verified by qPCR analysis of the expression levels of 16 selected genes, and the mean values of $\log _{2}$ fold change for each gene were consistent with the RNA-seq data (Supplementary Fig. S3).

To annotate transcripts from gene products, we identified the functions of transcripts using the Gene Ontology (GO) and Kyoto Encyclopedia of Genes and Genomes (KEGG) databases. Based on GO classification, the DEGs were classified into three categories: biological processes, molecular functions, and cellular components. The top 30 enriched GO terms among the DEGs at 36 and $72 \mathrm{hpi}$ are illustrated in Supplementary Figure S4. Under biological processes, "protein phosphorylation" followed by "phosphorylation" were the most enriched at $36 \mathrm{hpi}$, while "apoptotic process" and "programmed cell death" were the top two enriched GO terms at 72 hpi. Under molecular functions, the DEGs were mostly enriched in "pepsin A activity" followed by "phosphotransferase activity, alcohol group as acceptor" and "protein kinase activity" at 36 hpi; "phospholipid binding" and "calcium-dependent phospholipid binding" were the most enriched GO terms at $72 \mathrm{hpi}$. In addition, under cellular components, a large number of DEGs were enriched in membrane followed by terms involved in vesicle (Supplementary Table S3).

By mapping the transcripts to the reference canonical pathways in the KEGG database, 747 of 1,514 DEGs at 36 hpi were assigned to 94 pathways, and 72 of 165 DEGs at 72 hpi were grouped into 36 pathways. At $36 \mathrm{hpi}$, the KEGG pathway with the highest enrichment of DEGs was plant-pathogen interaction, and most DEGs enriched in this pathway were associated with pathogen-associated molecular pattern-triggered immunity (PTI). At $72 \mathrm{hpi}$, only protein processing in the endoplasmic reticulum (ER), spliceosome, and 2-oxocarboxylic acid metabolism were enriched significantly (Supplementary Table S3).

\section{DISCUSSION}

Previously, two T3SS gene clusters have been found in $M$. amorphae CCNWGS0123 (GS0123), a rhizobia strain nodulating $R$. pseudoacacia (Wang et al. 2019). However, the role of specific T3Es, especially NopP, in the establishment of rhizobialegume symbiosis has not been clarified. Here, we found that nopP_GS0123 is located in the symbiotic plasmid and is up-regulated under flavonoids induced in vitro, which is similar to genes encoding the structural components of T3SS-I. Thus, nopP_GS0123 can be induced by flavonoids secreted from $R$. pseudoacacia roots. A secretion assay showed that NopP was an

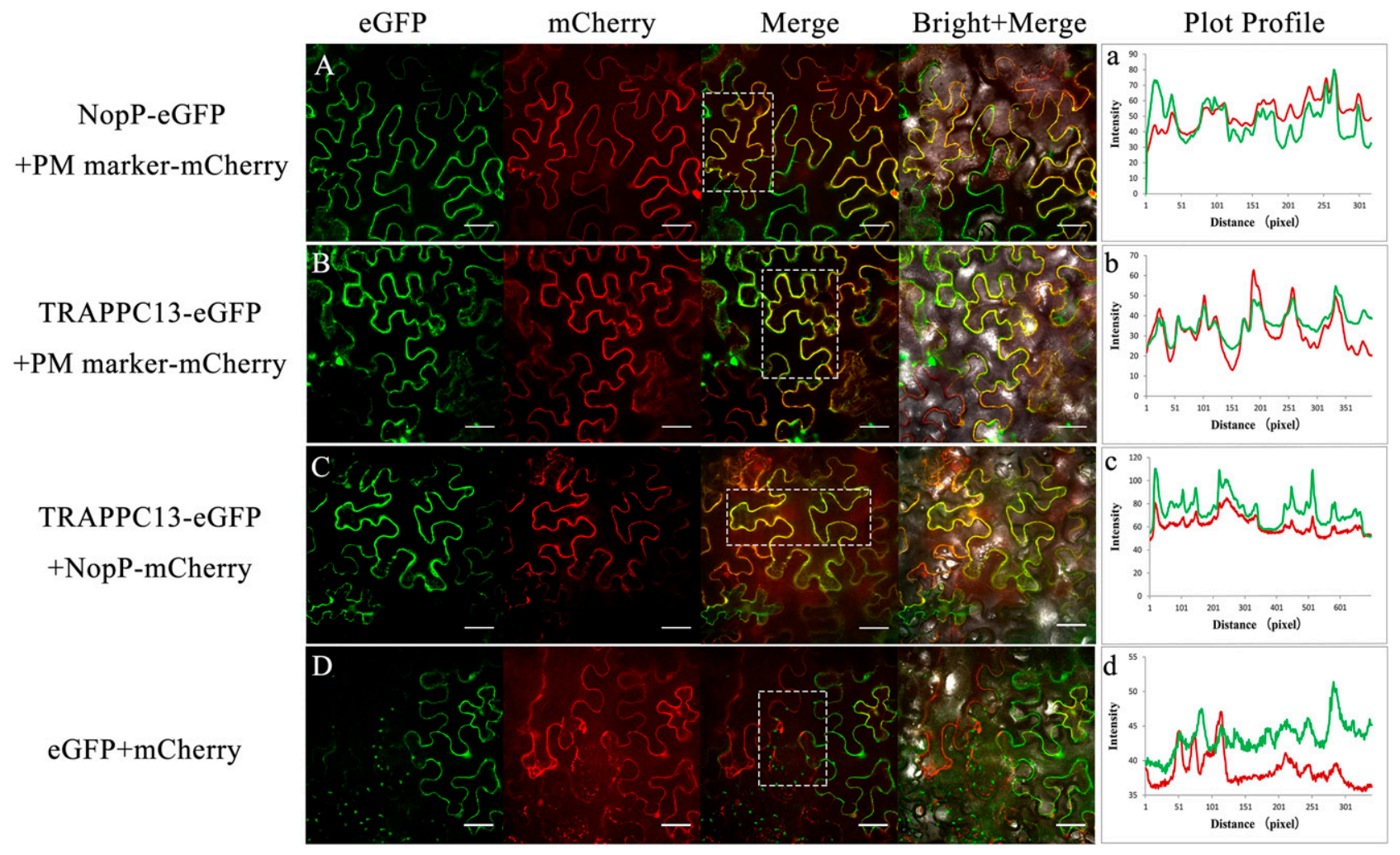

Fig. 5. Subcellular localization and colocalization of NopP and TRAPPC13 on the plasma membrane (PM) in Nicotiana benthamiana leaves. Correlation plot profiles between enhanced green fluorescent protein (eGFP) and mCherry fluorescence. A, Colocalization of NopP and PM marker, B, TRAPPC13 and PM marker, and C, NopP and TRAPPC13, and D, coexpressed of eGFP and mCherry as control. Fluorescence intensity profiles of eGFP (green) and mCherry (red) according to the distance (pixels, white dotted box in Merge images) were analyzed using Image J (National Institutes of Health, Bethesda, MD, U.S.A.). Scale bar $=50 \mu \mathrm{m}$. 

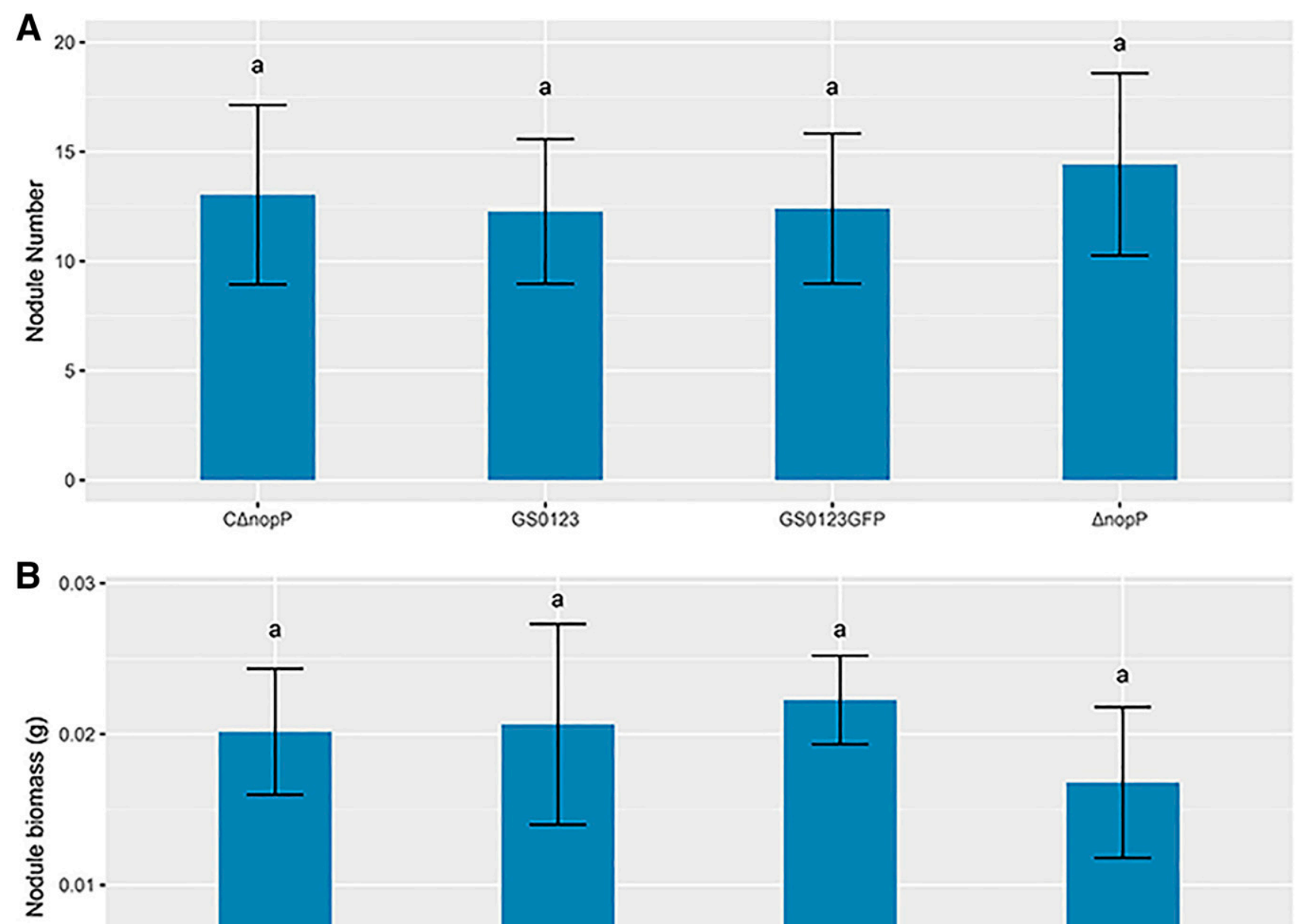

$0.00-$
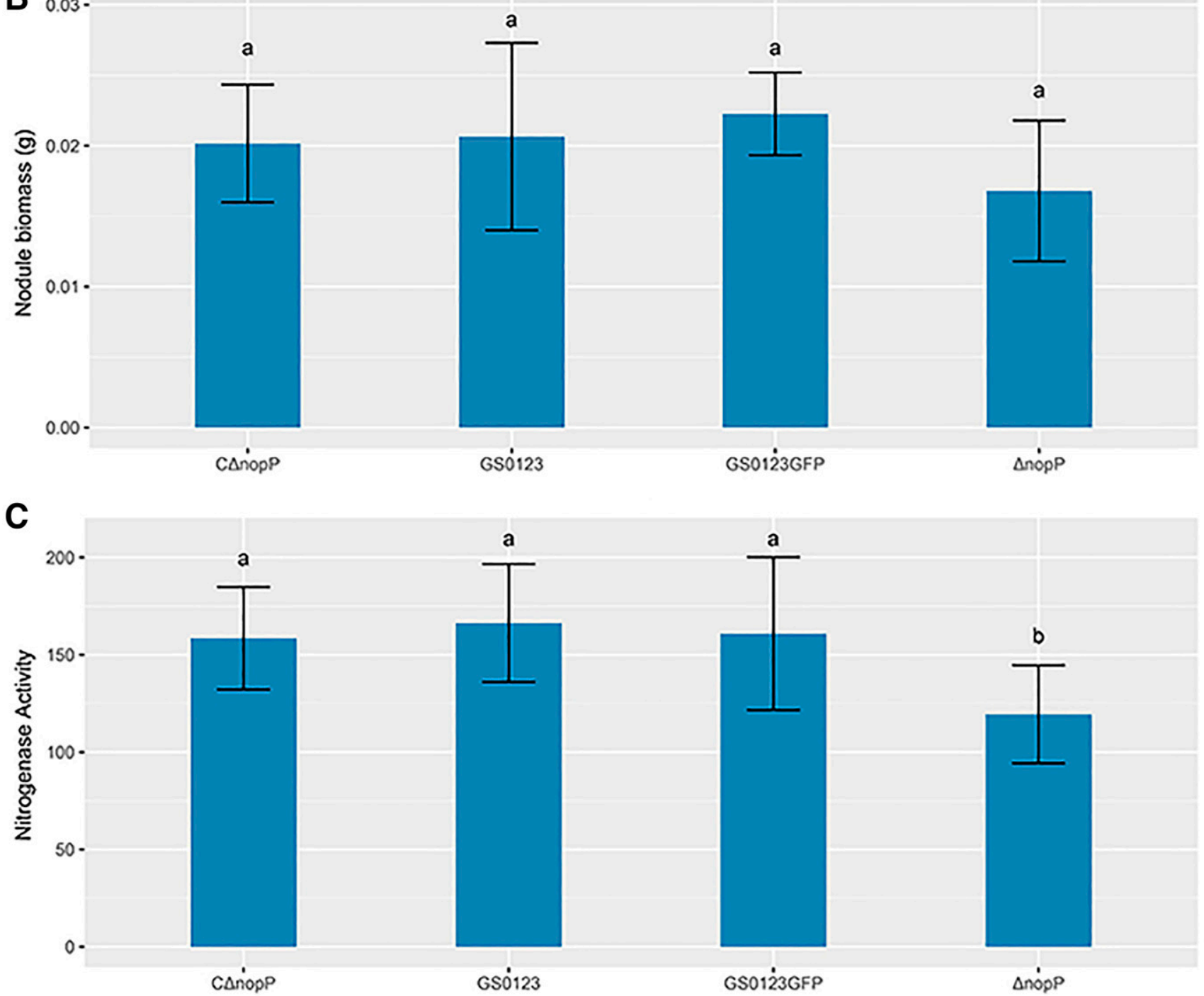

Fig. 6. Comparison of nodule traits in roots of Robinia pseudoacacia plants inoculated with the wild-type strain of Mesorhizobium amorphae CCNWGS0123 (GS0123), the nopP mutant strain ( $\triangle$ nopP-GS0123), its complementary strain (C $\Delta$ nopP-GS0123), and the wild-type strain containing the complementary vector carrying green fluorescent protein (GFP) (GS0123GFP) ( $n=100$ each). A, Nodule number per plant. B, Nodule biomass per group (each group had 15 plants, and six groups were measured). C, Nodule nitrogenase activity per group (each group had 15 plants, and six groups were measured). Different lowercase letters above the column indicate significant differences among the treatments $(P<0.05)$. 
effector of T3SS-I in GS0123. Within the first 3 dpi, we observed an evident increase in the levels of expression of nopP_GS0123 in $R$. pseudoacacia roots, which indicates that nopP_GS0123 is involved in the molecular signaling between M. amorphae CCNWGS0123 and its legume host during the early stages of infection.

Using $\mathrm{Y} 2 \mathrm{H}$ and subcellular localization assays, we observed that NopP interacts directly with TRAPPC13 on the PM. TRAPPC13 usually functions as a part of TRAPP complexes (Kim et al. 2016; Lipatova et al. 2016). These complexes share core TRAPPs, which are combined with complex-specific subunits (Lipatova et al. 2016). TRAPPC13 is a TRAPP II-specific subunit in yeast but a TRAPP III-specific subunit in metazoans (Kalde et al. 2019; Sacher et al. 2019). TRAPP II complex acts as a guanine nucleotide exchange factor (GEF) for Ypt31/32 to regulate Golgi-to-PM transport in yeast, while TRAPP III complex activates Rab1 as a GEF and participates in autophagy and ER-to-Golgi transport and the coat protein II recruitment to ER in metazoans (Kim et al. 2016; Lipatova and Segev 2019; Yu and Liang 2012). Loss of TRAPPC13 in Hela cells reduces apoptosis, impairs autophagic flux, and increases susceptibility to Shigella flexneri infection (Ramírez-Peinado et al. 2017). Trs65, the homolog of TRAPPC13 in yeast, contributes to GEF activity of TRAPP II in concert with two essential subunits, TRS120 and TRS130 (Liang et al. 2007). The deletion of Trs65 leads to lower Trs130 protein level (Liang et al. 2007). RNA-seq data shows significant increased expression levels of trs 120 and trs130 (Gene IDs i5_LQ_ABWTN_c4911/f1p0/5138 and i4_LQ_ABWTN_c7102/f1p0/4434) in $\bar{\Delta} n o p P$-inoculated roots at 36 hpi, suggesting that NopP may inhibit the expression of



Fig. 7. Morphological and physiological characteristics of Robinia pseudoacacia plants inoculated with Mesorhizobium amorphae CCNWGS0123. A, Growth status of plants inoculated with the wild-type strain (GS0123), the nopP knockout mutant strain ( $\Delta$ nopP-GS0123), and sterile water (Control). B, Paraffin section of root nodules at 30 days postinoculation (dpi). C, Paraffin section of the nitrogen fixation zone in 30-dpi nodules. D, Transmission electron microscopic images of symbiosomes in 30-dpi nodules. E, A photograph of uninoculated plant roots (the absence of nodules in the control group demonstrated that the experiment was not contaminated by other rhizobia). F, Image of all nodules on a random plant at 30 dpi. 
Trs120 and Trs130. Additionally, the mutation of Trs65/Kre11 reduces the $50 \%$ level of yeast cell wall $(1 \rightarrow 6)$-glucan and increases sensitivity to oxidative-stress reagents (Brown et al. 1993; Liang et al. 2007). These results indicate that Trs65/Kre11 plays roles in cell-wall biogenesis (Brown et al. 1993) and oxidative-stress response (Fernandez-Ricaud et al. 2007). During the initiation of infection, rhizobia induce plant cell-wall remodeling enzymes, such as pectic enzymes, pectin methyl esterase, polygalacturonase, and pectate lyase (Fåhhaeus and Ljunggren 1959; Muñoz et al. 1998; Xie et al. 2012), which are required for root-hair deformation and ITs formation (Brewin 2004). Although the mechanism has not been fully elucidated, some studies have reported that Nod factors can induce localized cell-wall degradation (Carol and Dolan 2002; van Spronsen et al. 1994). In this study, some genes associated with cell-wall remodeling were down-regulated significantly in $\Delta n o p P$-inoculated roots at $36 \mathrm{hpi}$, including xyloglucan endotransglucosylase, pectinesterase, pectin methyltransferase, and glucan 1,3-beta-glucosidase. Conceivably, NopP may be related to the localized cell-wall degradation and remodeling via interacting with TRAPPC13 in the early infection.

In Arabidopsis, TRAPP II component mutants exhibit dwarfism, sterility, and partial photomorphogenesis in the dark and show obvious defects in cytokinesis, cross-wall formation, cell polarity, polarity of the auxin transporter PIN2, and seedling development (Garcia et al. 2020; Ravikumar et al. 2018; Rybak et al. 2014; Zhang et al. 2018), while the function of TRAPP III is still unknown in plants. The transformation of small GTPases from an inactive to active state is catalyzed by specific GEF (Goody et al. 2017; Rehman and Di Sansebastiano 2014). Trs65

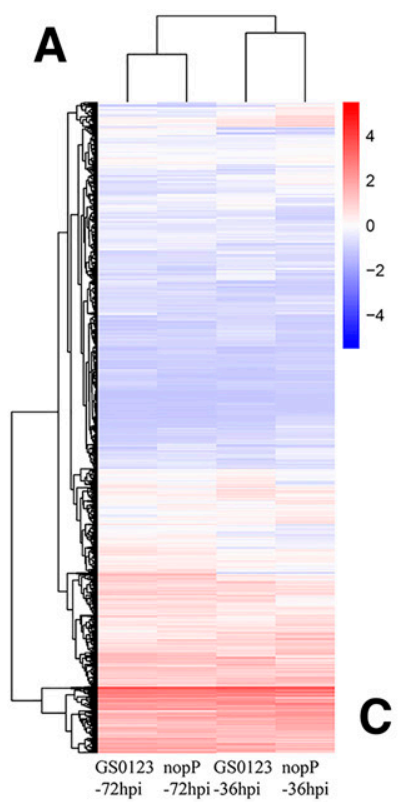

C

흄

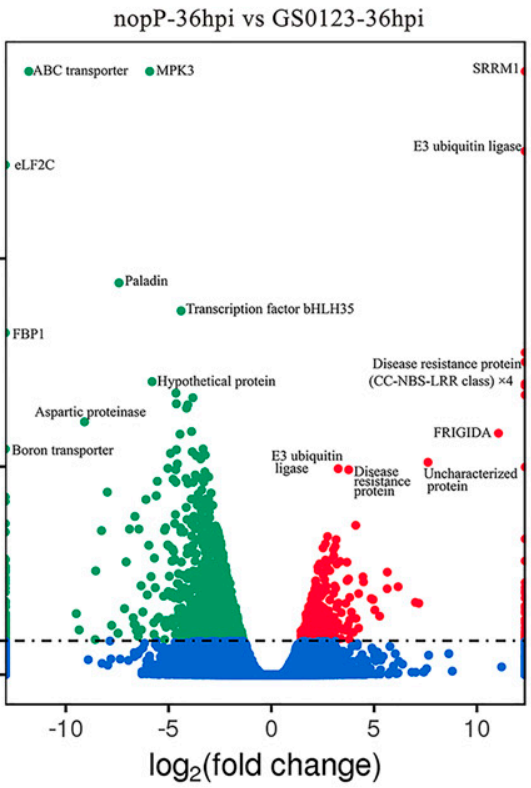

Differential Expressed Genes ( 1514 )

- up regulated: 321

- down regulated: 1193

B

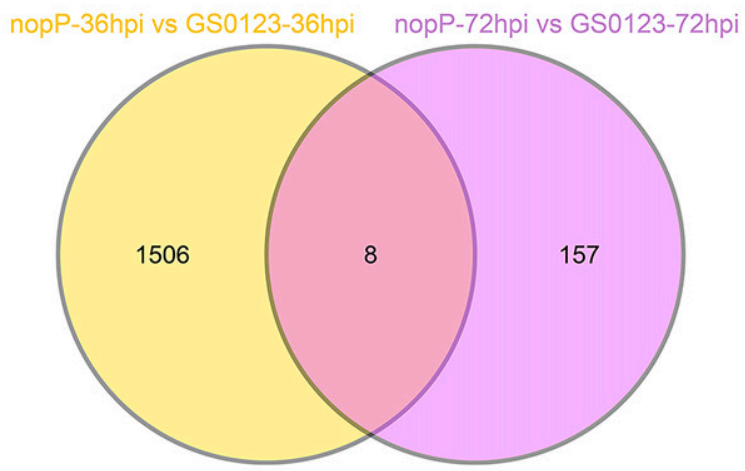

D

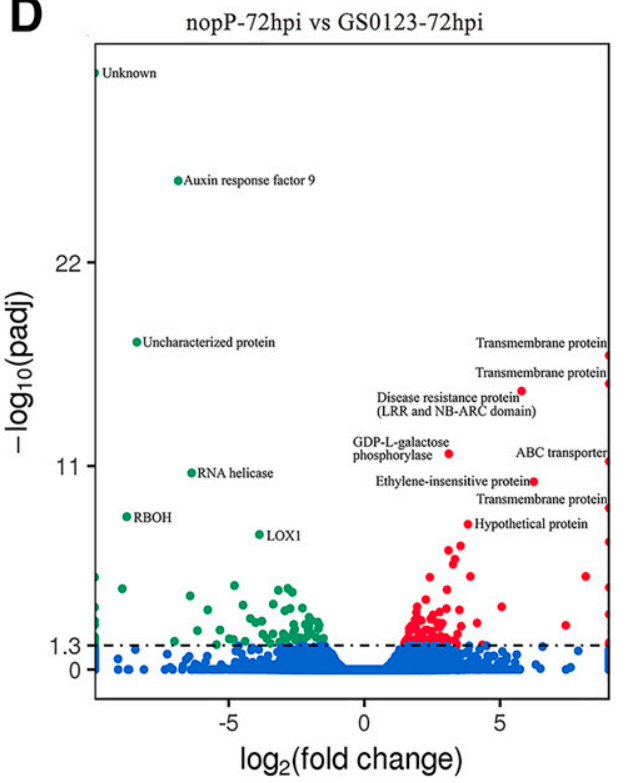

Differential Expressed Genes ( 165 )

- up regulated: 93

- down regulated: 72

Fig. 8. Overview of transcriptome analysis of differentially expressed genes (DEGs) in GS0123- and $\Delta$ nopP-inoculated Robinia pseudoacacia roots at $36 \mathrm{~h}$ postinoculation (hpi) (GS0123-36hpi and nopP-36hpi) and $72 \mathrm{hpi} \mathrm{(GS0123-72hpi} \mathrm{and} \mathrm{nopP-72hpi).} \mathrm{A,} \mathrm{A} \mathrm{heatmap} \mathrm{depicting} \mathrm{the} \mathrm{expression} \mathrm{changes}$ in all the DEGs. B, A Venn diagram showing the comparative analysis of a set of genes changed at 36 hpi (yellow circle) and 72 hpi (purple circle). C and D, Volcano plots of DEGs between two different libraries at 36 and $72 \mathrm{hpi}$, respectively, with $\log _{2}$ (fold-change) as the $x$ axis and - $\log _{10}$ (padj) as the $y$ axis. Red dots indicate upregulated DEGs, green dots indicate downregulated DEGs, and blue dots indicate nonsignificant DEGs. 
deletion leads to lower Ypt31 GEF activity in yeast, while TRAPPC13 deletion reduces Rab1a and Rab1b activity in Hela cells (Liang et al. 2007; Ramírez-Peinado et al. 2017). As molecular switches, Rab small GTPases are related to vesicle trafficking and signaling pathways involving hormones and biotic stresses (Rehman and Di Sansebastiano 2014). Among eight groups of plant Rab small GTPase, RabA (ortholog of Ypt31/32 in yeast and Rab11 in mammals) is extremely expanded and bears the unique characteristics in the plants (Minamino and Ueda 2019; Rehman and Di Sansebastiano 2014). Further, it has been identified that Rab small GTPases play important biological roles in nodule meristem activity and maintenance at an early stage of the infection process by alternating between GDPbound (inactive) and GTP-bound (active) states (Flores et al. 2018; Wang et al. 2020; Yuksel and Memon 2008). Mutations of RabA2 result in bursting of ITs and a reduction in nodule number in Phaseolus vulgaris (Dalla Via et al. 2017). RabA2 is required for root-hair deformation and the progression and maintenance of membrane integrity of ITs by regulating vesicle trafficking of the materials involved in PM and cell-wall remodeling (Blanco et al. 2009; Dalla Via et al. 2017). In addition, Rab1p is essential for the development of the symbiosome membrane in effective symbiosis (Cheon et al. 1993). Recently, it has been demonstrated that SPIKE1 interacts with and activates the small GTPase LjROP6 as a GEF to guide the polar progression of ITs in Lotus japonicus (J. Liu et al. 2020). Thus, we infer that TRAPPC13 could be involved in the formation of ITs in $R$. pseudoacacia by activating the small GTPase.

In Arabidopsis and tomato, the T3E AvrPto from pathogenic bacteria Pseudomonas syringae targets FLAGELLIN SENSING 2 (FLS2) and RabE to block innate immunity (Bogdanove and Martin 2000; Speth et al. 2009; Xiang et al. 2008). Based on KEGG pathway analysis, 38 genes related to PTI, including calcium-dependent protein kinase, respiratory burst oxidase protein, calcium-binding protein CML, mitogen-activated protein kinase kinase 1 (MAPKK 1), MAPKK 1/2, and WRKY transcription factor, were down-regulated significantly in $\Delta n o p P$-inoculated roots at $36 \mathrm{hpi}$, suggesting that NopP can activate PTI downstream of FLS2. But this activation effect cannot be sustained, because the expression levels of related genes, except genes encoding respiratory burst oxidase isogeny protein A, are no different from those in the GS0123-inoculated roots at $72 \mathrm{hpi}$. Subcellular localization of FLS2 is strictly regulated by membrane trafficking. RabA subgroup members not only act in flg22 peptide-induced endocytosis of FLS2 from PM to compartments but also act in transport of newly synthesized FLS2 to the PM (Choi et al. 2013). For example, RabA4b collaborates with PLANT U-BOX13 E3 ubiquitin ligases and PI(4)P to attenuate FLS2-dependent immune responses by mediating ligand-induced degradation of the FLS2 (Lu et al. 2011; Minamino and Ueda 2019). RabA6a and RabA4c also regulate different steps in the endocytic trafficking of FLS2, while Rab1b facilitates the secretion of de novo-synthesized FLS2 to the PM (Choi et al. 2013). These findings suggest that the interaction between NopP and TRAPPC13 reduces the activity of RabA, leading to the transient stronger expression of genes related to PTI, which was inhibited subsequently during the infection.

Although evidence of the importance of Rab small GTPases of rhizobial infection have been obtained in a variety of ways, we did not observe significant changes in phenotypes of $R$. pseudoacacia inoculated with $\triangle$ nopP mutant strains except for a slight decrease in both nodule volume and nitrogenase activity. There are many possibilities for this result. First, multiple effectors work together to facilitate the establishment of symbiosis with legume hosts, while a single effector can play a limited role during rhizobial infection. Second, small GTPase is a large protein family with many functional redundancies, and Trs65 has been identified to be a nonessential subunit due to its function overlap with Trs33 in the TRAPP II assembly in yeast (Liang et al. 2007; Tokarev et al. 2009). As a homolog of Trs65, TRAPPC13 may also be replaced by Trs33 in some cases. In addition, most of the differences in the expression of related genes are only present at $36 \mathrm{hpi}$ and could not be sustained, which weakened the influence of nopP deficiency on the establishment of the symbiotic system. In order to understand how TRAPPCs work in plants and how membrane trafficking has been adapted in the rhizobia-legume symbiotic system, much more research is needed. In conclusion, NopP is an effector of T3SS-I in M. amorphae CCNWGS0123, playing a role at the early stage of infection. We have demonstrated the interaction of NopP with a novel target protein (TRAPCC13) in the $\mathrm{PM}$. The results of this study could enhance our understanding of the role of NopP in the establishment of rhizobia-legume symbiotic systems.

\section{MATERIALS AND METHODS}

Construction of mutant and complementary strains.

In this study, nopP was knocked out from the wild-type strain GS0123 of $M$. amorphae CCNWGS0123 by homologous recombination to construct a mutant strain, named $\Delta$ nopP GS0123. The homologous arm was constructed by overlapping PCR and was linked to the suicide plasmid pK18mobsacB, and was then transferred into $M$. amorphae CCNWGS0123 by electrotransformation. Double-exchange mutants were selected on TY agar plates containing 5\% sucrose (Ausmees et al. 2004) and were validated by sequencing. The amplification primers of the upstream homologous arms were 5'-ATCATGGGAAAGA ACGGAGACG-3' and 5'-TGAACCAAGGATAAGGCACCA-3', and the primers of the downstream homologous arms were $5^{\prime}$ TCACTTTTCTGGCGAATGAAGACC-3' and 5'-CGGGCTCTG GTTAGACGATTG-3'. Both pairs of primers were designed using Primer Premier v5 (Premier Biosoft International). To construct a complementary strain, nopP was inserted into pBBR1-mcs5; afterward, the recombinant vector was transferred into the $\Delta$ nopP_GS0123 mutant strain.

\section{Plant growth and rhizobial infection.}

R. pseudoacacia seeds were soaked in $\mathrm{H}_{2} \mathrm{SO}_{4}$ for approximately $8 \mathrm{~min}$ to remove the surface wax layer; thereafter, the seeds were treated with $95 \%(\mathrm{vol} / \mathrm{vol})$ ethanol and $50 \%$ ( $\mathrm{vol} /$ vol) $\mathrm{NaClO}$ to sterilize the surface (Chen et al. 2013). The seeds were then washed with sterile water and were germinated in sterile Petri dishes in the dark. After seed germination, the seedlings were transplanted into plastic pouches (two seedings per pouch) containing $800 \mathrm{ml}$ of a sterilized mixture of vermiculiteperlite $(2: 1, \mathrm{vol} / \mathrm{vol})$ and $400 \mathrm{ml}$ of Fahraeus N-free nutrient solution (Chou et al. 2016; Liang et al. 2016). Seven days later, each pouch was inoculated with a 5-ml suspension (optical density at $600 \mathrm{~nm}=0.1$ ) of an M. amorphae CCNWGS0123 culture in TY broth. The inoculated plants were incubated in a controlled greenhouse (humidity, $70 \%$; day condition, $22^{\circ} \mathrm{C}, 16$ $\mathrm{h}$; night condition, $16^{\circ} \mathrm{C}, 8 \mathrm{~h}$ ) (Wang et al. 2019) and were harvested at different timepoints $(2,4,8,12,24,48,72$, and 120 hpi and 12 and $30 \mathrm{dpi}$ ). Approximately 30 pouches of uninoculated seedings were used as negative controls to ensure that the plants were not contaminated by other rhizobia.

\section{RNA extraction and qPCR analysis.}

Total bacterial RNA was extracted from purified rhizobial cultures of M. amorphae CCNWGS0123 grown in TY broth with or without flavonoid induction using the hot phenol method (Hosoda et al. 2003). A mixture of flavonoids (apigenin, luteolin, and naringenin) was added to the cultures, with final 
concentrations of $1 \mu \mathrm{M}$ (Scheidemann and Wetzel 1997; Veitch et al. 2010). Total plant RNA was extracted from infected roots and shoots of $R$. pseudoacacia plants using the MiniBEST plant RNA extraction kit (TaKaRa). First-strand cDNA was synthesized using the PrimeScript RT reagent kit (TaKaRa). Bacterial cDNA was synthesized using random primers and plant cDNA was synthesized with primer Oligo (dT).

qPCRs were performed using the EvaGreen qPCR MasterMix (Abm, Canada). All primers used for qPCR (Supplementary Table S2) were designed using Primer premier v5 (Premier Biosoft International). The qPCR was performed on a QuantStudio 6 Flex real-time PCR system (Life Technologies). The obtained data were normalized to $16 \mathrm{~S}$ rRNA and $18 \mathrm{~S}$ rRNA expression and were then analyzed using the Quantstudio 6 real-time PCR software. Quantification of gene expression was performed using the relative quantification $\left(2^{-\Delta \Delta C T}\right)$ method, and comparisons of the means were performed by using the $\log _{2}$-transformed data. The DEGs were considered induced or repressed if the normalized fold change was $>2$.

\section{Secretion assay.}

M. amorphae CCNWGS0123 wild-type strain and T3SS-I and T3SS-II deficient mutant strains, whose $r h c N 1 / r h c N 2$ encoding ATPases were disrupted, were grown at $28^{\circ} \mathrm{C}$ with flavonoid induction for $48 \mathrm{~h}$, respectively. Supernatant proteins were collected from GS0123 wild-type strain, T3SS-I mutant strain, and T3SS-II mutant strain culture medium by three consecutive centrifugations (using a Sigma 3K15), one at 5,500 $\mathrm{rpm}$ and the others at 7,500 rpm. Then, ammonium sulfate was added into bacteria-free culture medium at a final saturation of $80 \%$. Samples were desalted overnight by dialysis bag and were concentrated by ultrafiltration (Merck Millipore) (Marie et al. 2003; Sánchez et al. 2009). Extracellular proteins were separated by electrophoresis on sodium dodecyl sulfate-polyacrylamide gel electrophoresis (SDS-PAGE) and were stained with Coomassie blue. As the molecular mass of NopP is about $31 \mathrm{kDa}$, the bands between 25 and $35 \mathrm{kDa}$ were cut and detected by mass spectrometry.

\section{Plant symbiosis analysis.}

At $30 \mathrm{dpi}, R$. pseudoacacia plants inoculated with the wildtype strain of $M$. amorphae CCNWGS0123 (GS0123), the $\Delta n o p P$ GS0123 mutant strain ( $\Delta$ nopP-GS0123), its complementary strain (CAnopP-GS0123), and the wild-type strain containing the complementary vector carrying GFP (GS0123GFP) were harvested. To examine symbiosis establishment, we measured plant height, plant biomass, root length, nodule number, and nodule biomass. In addition, the nitrogenase activity of root nodules was monitored using acetylene reduction assay (Das and De 2018). Briefly, fresh nodules from every 15 plants were placed in 10-ml sealed glass bottles, and $400 \mu \mathrm{m}$ of acetylene gas was injected into each bottle with a sample injector. The nodule samples were allowed to react in darkness at $28^{\circ} \mathrm{C}$ for 2 $\mathrm{h}$. Afterward, the ethylene concentrations were analyzed by gas chromatography (Trace GC Ultra, Thermo Fisher Scientific). Chlorophyll concentrations in leaf samples at similar positions (two leaves per plant) were measured using a portable chlorophyll meter (SPAD-502 plus, Minolta Camera Co. Ltd.). Each sample had three biological replicates.

To observe the structures of root nodules, their morphology was examined microscopically using paraffin sections. Fresh nodules were wrapped in paraffin and cut into 5- $\mu \mathrm{m}$ slices, stained with $0.05 \%$ toluidine blue for approximately $5 \mathrm{~min}$, to visualize bacteroids inside the nodule cells. After staining, the samples were washed using distilled water and were then observed under an optical microscope (BX53; Olympus). In addition, ultrathin sections were prepared to observe the internal morphology of the $\mathrm{N}_{2}$-fixing cells in the root nodules. The $\mathrm{N}$ fixation zones of fresh nodules were cut into $2 \times 2 \mathrm{~mm}^{2}$ blocks, and the blocks were immersed in glutaraldehyde for $24 \mathrm{~h}$, followed by $1 \%$ (vol/vol) osmium tetroxide for $2 \mathrm{~h}$. Subsequently, the blocks were subjected to gradient dehydration with 30 to $100 \%$ ethanol, and then, were embedded in 812 resin. Resin polymerization was performed at $55^{\circ} \mathrm{C}$ for more than $48 \mathrm{~h}$, and the ultrathin sections were observed using a transmission electron microscope (HT7700, Hitachi) (Zou et al. 2020).

\section{Y2H screening of NopP interacting proteins.}

To screen for the targets of NopP in $R$. pseudoacacia root cells, a cDNA library was prepared from GS0123-inoculated roots using a SMART cDNA library construction kit (Clontech). The roots were sampled at different timepoints, mainly during the early stages of infection. Total RNA was extracted, mixed, reverse-transcribed, and then, was used to construct a three-reading-frame normalized root cDNA library, in which each gene could express the same proteins expressed in live plants, and each protein had the similar chances of binding to the bait.

nopP_GS0123 was cloned into the bait vector pGBKT7 and cotransformed into Y2HGold yeast strain with cDNA (pGADT7-SfilB) from the constructed root cDNA library. Subsequently, the transformed yeast was spread onto double amino acid (-Leu/-Trp) dropout (DDO) plates. The DDO colonies were streaked onto QDO/X/A plates. The pGADT7-T (encoding SV40 large T-antigen ${ }_{[84-708]}$ ) and pGBKT7-53 (encoding murine p53 protein $\left.{ }_{[72-390]}\right)$ are known to interact and served as the positive control, while pGADT7-T and pGBKT7-Lam (encoding Human lamin $C_{[66-230]}$ ) were used as negative controls because lamin $\mathrm{C}$ does not interact with most other proteins (Wong et al. 2002). The vector blue colonies from QDO/X/A plates were isolated, and the purified colonies were screened by colony PCR using Matchmaker Insert Check PCR Mix 2 (Clontech). The colonies with only one electrophoretic band were sequenced, and all unigenes were searched using BlastX (Altschul et al. 1997).

\section{Verification of protein-protein interaction by BiFC and Co-IP assays.}

First, a BiFC assay was carried out with binary vectors pSPYNE-35S and pSPYCE-35S. NopP was fused with YFP $^{\mathrm{C}}$ into pSPYCE-35S and its candidate targets were fused with $\mathrm{YFP}^{\mathrm{N}}$ into pSPYNE-35S. Afterward, the constructed vectors were transferred into A. tumefaciens GV3101 separately and were expressed transiently in 3 - to 4-week-old $N$. benthamiana leaves. BiFC-induced yellow florescence was observed 3 days after agroinfiltration under a confocal laser-scanning microscope (Andor Revolution WD) (Bhat et al. 2006; Verhoef and Wade 2017).

Next, a Co-IP assay was used to confirm the interaction between NopP and its candidate targets. NopP fused with Flag-tag was cloned into the pEarleyGate202-YC vector and its candidate targets fused with HA-tag were cloned into the pEarleyGate201YN vector. The constructs were transformed into A. tumefaciens GV3101 and then infiltrated into 3- to 4-week-old N. benthamiana leaves. Three days after agroinfiltration, the fusion proteins were extracted from leaf samples expressing Co-IP constructs, using a lysis buffer $(150 \mathrm{mM} \mathrm{NaCl}, 25 \mathrm{mM}$ Tris- $\mathrm{HCl}, \mathrm{pH} 7.5,1$ $\mathrm{mM}$ EDTA, and $0.5 \%$ NP-40) supplemented with $1 \mathrm{M}$ dithiothreitol. The samples were incubated on ice for $15 \mathrm{~min}$ and were then centrifuged at $12,000 \times g$ at $4^{\circ} \mathrm{C}$ for $15 \mathrm{~min}$. The supernatant was filtered with a $45-\mu \mathrm{m}$ filter membrane, and a small amount of the filtered proteins was used as the input material for SDS-PAGE. The remainder of the proteins was incubated at $4^{\circ} \mathrm{C}$ with anti-HA-tag magnetic beads for $3 \mathrm{~h}$. After removing the supernatant, beads were washed with a wash buffer $(150 \mathrm{mM} \mathrm{NaCl}, 0.5 \mathrm{mM}$ EDTA, and $10 \mathrm{mM}$ Tris- $\mathrm{HCl}$, pH 7.5) for $5 \mathrm{~min}$. Both the input and resuspended Co-IP samples 
were boiled for $5 \mathrm{~min}$ to dissociate the immunocomplexes ( $\mathrm{Li}$ et al. 2019). Following a 2-min ice bath, centrifugation and electrophoresis were carried out. Western blotting was used to detect the immunoprecipitation of the two proteins.

\section{Subcellular localization of NopP and its target TRAPPC13.}

To locate NopP and its target protein TRAPPC13 in plant cells, the vectors $p 35 S:: n o p P-e G F P$ p35S::nopP-mCherry and p35S::trappc13-eGFP were generated. NopP and TRAPPC13 were digested with $X m a I$ and SpeI restriction enzymes and were inserted into a binary expression vector called pYJGFP, to generate NopP-eGFP and TRAPPC13-eGFP fusion protein, respectively, under the control of the cauliflower mosaic virus $35 \mathrm{~S}$ promoter [66]. Subsequently, the modified vectors were transformed into A. tumefaciens GV3101. Simultaneously, mCherry-labeled PM marker was used in the colocalization experiment, and the empty vectors (p35S::mCherry and p35S::eGFP) were used as control, providing information about infiltration-induced leaf fluorescence. Leaves of 3- to 4-weekold $N$. benthamiana plants were infiltrated with A. tumefaciens GV3101 in an agroinfiltration medium consisting of $10 \mathrm{mM}$ $\mathrm{MgCl}_{2}, 10 \mathrm{mM}$ morpholineethane sulfonic acid, and $150 \mathrm{mM}$ acetosyringone (S. Liu et al. 2020). After 48 to $72 \mathrm{~h}$ of incubation, signals were detected under a confocal laser-scanning microscope (Andor Revolution WD).

\section{mRNA transcriptome analysis.}

For RNA-seq, GS0123- and $\Delta n o p P$-inoculated roots of $R$. pseudoacacia were sampled at 36 and 72 hpi. The mRNA was purified from total RNA and cDNA was synthesized. The cDNA was amplified to generate cDNA libraries, and secondgeneration high-throughput sequencing was performed on an Illumina HiSeq 2000 platform (Illumina Inc.) by Allwegene, using a paired-end sequencing strategy (150 bp). Meanwhile, total RNA from GS0123-infected roots were extracted to construct a cDNA combined SMRTbell library and third-generation sequencing was performed on a PacBio RS II platform (Pacific Biosciences). Three biological replicates for each sample were subjected to RNA extraction. Since no $R$. pseudoacacia reference genome is available, the full-length transcriptome (Iso-Seq) obtained by third-generation sequencing was used as the reference sequence (Supplementary Table S2), and clean reads of each sample were mapped to the reference sequence using the RSEM software (Li and Dewey 2011). The RNA-seq data are available at National Center for Biotechnology Information Short Read Archive under Bioproject PRJNA644405.

The DEG input data were read count data obtained from gene expression analyses. $R$. pseudoacacia genes of $\Delta$ nop $P$-inoculated roots with signal intensities more than twofold (or 0.5 -fold) that of GS0123-inoculated roots were considered upregulated (or downregulated). DESeq was used for data analysis (Anders and Huber 2010), and the screening threshold was padj $<0.05$. GO enrichment analysis was performed using the GOseq software based on Wallenius noncentral hypergeometric distribution (Young et al. 2010), and KEGG enrichment analysis was performed using KOBAS v2.0.

\section{Statistical analyses.}

Data were presented as the means \pm standard deviation of three biological replicates. Different capital letters indicated significant differences $(P<0.05)$ of the different strains inoculated. Significant differences between means of samples were checked by analysis of variance and the Student's $t$ tests ( $\alpha=$ 0.05). Statistical analyses were performed by SPSS 19.0 (SPSS Inc.), and figures were performed with Origin 2019 (OriginLab Corp) and Microsoft Excel 2010.

\section{ACKNOWLEDGMENTS}

The authors thank the Life Science Research Core Services for its support and assistance.

\section{AUTHOR-RECOMMENDED INTERNET RESOURCES}

BlastX tool: https://blast.ncbi.nlm.nih.gov/Blast.cgi

KOBAS v2.0: http://kobas.cbi.pku.edu.cn

National Center for Biotechnology Information Short Read Archive: https://www.ncbi.nlm.nih.gov/bioproject/644405

\section{LITERATURE CITED}

Altschul, S. F., Madden, T. L., Schäffer, A. A., Zhang, J., Zhang, Z., Miller, W., and Lipman, D. J. 1997. Gapped BLAST and PSI-BLAST: A new generation of protein database search programs. Nucleic Acids Res. 25:3389-3402

Anders, S., and Huber, W. 2010. Differential expression analysis for sequence count data. Genome Biol. 11:R106.

Ausmees, N., Kobayashi, H., Deakin, W. J., Marie, C., Krishnan, H. B., Broughton, W. J., and Perret, X. 2004. Characterization of NopP, a type III secreted effector of Rhizobium sp. strain NGR234. J. Bacteriol. 186:4774-4780.

Bartsev, A. V., Deakin, W. J., Boukli, N. M., McAlvin, C. B., Stacey, G., Malnoë, P., Broughton, W. J., and Staehelin, C. J. P. P. 2004. NopL, an effector protein of Rhizobium sp. NGR234, thwarts activation of plant defense reactions. Plant Physiol. 134:871-879.

Bhat, R. A., Lahaye, T., and Panstruga, R. 2006. The visible touch: In planta visualization of protein-protein interactions by fluorophore-based methods Plant Methods 2:12.

Blanco, F. A., Meschini, E. P., Zanetti, M. E., and Aguilar, O. M. 2009. A small GTPase of the Rab family is required for root hair formation and preinfection stages of the common bean-Rhizobium symbiotic association. Plant Cell 21:2797-2810.

Bogdanove, A. J., and Martin, G. B. 2000. AvrPto-dependent Pto-interacting proteins and AvrPto-interacting proteins in tomato. Proc. Natl. Acad. Sci. U.S.A. 97:8836-8840.

Boring, L., and Swank, W. T. 1984. The role of black locust (Robinia pseudoacacia) in forest succession. J. Ecol. 72:749-766.

Brewin, N. J. 2004. Plant cell wall remodelling in the rhizobium-legume symbiosis. Crit. Rev. Plant Sci. 23:293-316.

Brown, J. L., Kossaczka, Z., Jiang, B., and Bussey, H. 1993. A mutational analysis of killer toxin resistance in Saccharomyces cerevisiae identifies new genes involved in cell wall $(1->6)$-beta-glucan synthesis. Genetics 133:837-849.

Carol, R. J., and Dolan, L. 2002. Building a hair: Tip growth in Arabidopsis thaliana root hairs. Philos. Trans. R. Soc. Lond. B Biol. Sci. 357:815-821.

Chen, H., Chou, M., Wang, X., Liu, S., Zhang, F., and Wei, G. 2013. Profiling of differentially expressed genes in roots of Robinia pseudoacacia during nodule development using suppressive subtractive hybridization. PLoS One 8:e63930.

Cheon, C.-I., Lee, N.-G., Siddique, A. B., Bal, A. K., and Verma, D. P. 1993. Roles of plant homologs of Rab1p and Rab7p in the biogenesis of the peribacteroid membrane, a subcellular compartment formed de novo during root nodule symbiosis. EMBO J. 12:4125-4135.

Choi, S. W., Tamaki, T., Ebine, K., Uemura, T., Ueda, T., and Nakano, A. 2013. RABA members act in distinct steps of subcellular trafficking of the FLAGELLIN SENSING2 receptor. Plant Cell 25:11741187.

Chou, M., Xia, C., Feng, Z., Sun, Y., Zhang, D., Zhang, M., Wang, L., and Wei, G. 2016. A translationally controlled tumor protein gene Rpf41 is required for the nodulation of Robinia pseudoacacia. Plant Mol. Biol. 90:389-402.

Dalla Via, V., Traubenik, S., Rivero, C., Aguilar, O. M., Zanetti, M. E., and Blanco, F. A. 2017. The monomeric GTPase RabA2 is required for progression and maintenance of membrane integrity of infection threads during root nodule symbiosis. Plant Mol. Biol. 93:549-562.

Das, S., and De, T. K. 2018. Microbial assay of $\mathrm{N}_{2}$ fixation rate, a simple alternate for acetylene reduction assay. MethodsX 5:909-914.

Fåhhaeus, G., and Ljunggren, H. 1959. The possible significance of pectic enzymes in root hair infection by nodule bacteria. Physiol. Plant 12:145-154.

Fernandez-Ricaud, L., Warringer, J., Ericson, E., Glaab, K., Davidsson, P., Nilsson, F., Kemp, G. J., Nerman, O., and Blomberg, A. 2007. 
PROPHECY - A yeast phenome database, update 2006. Nucleic Acids Res. 35 (Database):D463-D467.

Flores, A. C., Via, V. D., Savy, V., Villagra, U. M., Zanetti, M. E., and Blanco, F. 2018. Comparative phylogenetic and expression analysis of small GTPases families in legume and non-legume plants. Plant Signal. Behav. 13:e1432956.

Garcia, V. J., Xu, S. L., Ravikumar, R., Wang, W., Elliott, L., Gonzalez, E., Fesenko, M., Altmann, M., Brunschweiger, B., Falter-Braun, P., Moore, I., Burlingame, A., Assaad, F. F., and Wang, Z. Y. 2020. TRIPP is a plant-specific component of the Arabidopsis TRAPPII membrane trafficking complex with important roles in plant development. Plant Cell 32:2424-2443.

Goody, R. S., Müller, M. P., and Wu, Y. W. 2017. Mechanisms of action of Rab proteins, key regulators of intracellular vesicular transport. Biol. Chem. 398:565-575.

Hao, X., Lin, Y., Johnstone, L., Baltrus, D. A., Miller, S. J., Wei, G., and Rensing, C. 2012. Draft genome sequence of plant growth-promoting rhizobium Mesorhizobium amorphae, isolated from zinc-lead mine tailings. J. Bacteriol. 194:736-737.

Hosoda, N., Kobayashi, T., Uchida, N., Funakoshi, Y., Kikuchi, Y., Hoshino, S., and Katada, T. 2003. Translation termination factor eRF3 mediates mRNA decay through the regulation of deadenylation. J. Biol. Chem. 278:38287-38291.

Janczarek, M., Rachwał, K., Marzec, A., Grządziel, J., and PalusińskaSzysz, M. 2015. Signal molecules and cell-surface components involved in early stages of the legume-rhizobium interactions. Appl. Soil Ecol. 85:94-113.

Jiménez-Guerrero, I., Pérez-Montaño, F., Medina, C., Ollero, F. J., and López-Baena, F. J. 2017. The Sinorhizobium (Ensifer) fredii HH103 nodulation outer protein NopI is a determinant for efficient nodulation of soybean and cowpea plants. Appl. Environ. Microbiol. 83:e02770-16.

Kalde, M., Elliott, L., Ravikumar, R., Rybak, K., Altmann, M., Klaeger, S., Wiese, C., Abele, M., Al, B., Kalbfuß, N., Qi, X., Steiner, A., Meng, C., Zheng, H., Kuster, B., Falter-Braun, P., Ludwig, C., Moore, I., and Assaad, F. F. 2019. Interactions between transport protein particle (TRAPP) complexes and Rab GTPases in Arabidopsis. Plant J. 100:279-297.

Kambara, K., Ardissone, S., Kobayashi, H., Saad, M. M., Schumpp, O., Broughton, W. J., and Deakin, W. J. 2009. Rhizobia utilize pathogenlike effector proteins during symbiosis. Mol. Microbiol. 71:92-106.

Kim, J. J., Lipatova, Z., and Segev, N. 2016. TRAPP complexes in secretion and autophagy. Front. Cell Dev. Biol. 4:20.

Kimbrel, J. A., Thomas, W. J., Jiang, Y., Creason, A. L., Thireault, C. A., Sachs, J. L., and Chang, J. H. 2013. Mutualistic co-evolution of type III effector genes in Sinorhizobium fredii and Bradyrhizobium japonicum. PLOS Pathog. 9:e1003204.

Li, B., and Dewey, C. N. 2011. RSEM: Accurate transcript quantification from RNA-seq data with or without a reference genome. BMC Bioinformatics 12:323.

Li, T., Wang, Q., Feng, R., Li, L., Ding, L., Fan, G., Li, W., Du, Y., Zhang, M., Huang, G., Schäfer, P., Meng, Y., Tyler, B. M., and Shan, W. 2019. Negative regulators of plant immunity derived from cinnamyl alcohol dehydrogenases are targeted by multiple Phytophthora Avr3a-like effectors. New Phytol. Published online.

Li, W., Mingan, S., and Yuyuan, L. 2004. Study on relationship between growth of artificial Robinia pseudoacacia plantation and soil desiccation in the Loess Plateau of Northern Shaanxi Province. Scientia Silvae Sinicae 40:84-91.

Liang, J., Zhang, M., Lu, M., Li, Z., Shen, X., Chou, M., and Wei, G. 2016. Functional characterization of a csoR-cueA divergon in Bradyrhizobium liaoningense CCNWSX0360, involved in copper, zinc and cadmium cotolerance. Sci. Rep. 6:35155.

Liang, Y., Morozova, N., Tokarev, A. A., Mulholland, J. W., and Segev, N. 2007. The role of Trs65 in the Ypt/Rab guanine nucleotide exchange factor function of the TRAPP II complex. Mol. Biol. Cell 18:2533-2541.

Lipatova, Z., Majumdar, U., and Segev, N. 2016. Trs33-containing TRAPP IV: A novel autophagy-specific Ypt1 GEF. Genetics 204:1117-1128.

Lipatova, Z., and Segev, N. 2019. Ypt/Rab GTPases and their TRAPP GEFs at the Golgi. FEBS Lett. 593:2488-2500.

Liu, J., Liu, M. X., Qiu, L. P., and Xie, F. 2020. SPIKE1 Activates the GTPase ROP6 to guide the polarized growth of infection threads in Lotus japonicus. Plant Cell 32:3774-3791.

Liu, S., Ma, J., Liu, H., Guo,Y., Li, W., and Niu, S. 2020. An efficient system for Agrobacterium-mediated transient transformation in Pinus tabuliformis. Plant Methods 16:52.

López-Baena, F. J., Monreal, J. A., Pérez-Montaño, F., Guasch-Vidal, B., Bellogín, R. A., Vinardell, J. M., and Ollero, F. J. 2009. The absence of
Nops secretion in Sinorhizobium fredii HH103 increases GmPR1 expression in Williams soybean. Mol. Plant-Microbe Interact. 22:1445-1454.

López-Baena, F. J., Ruiz-Sainz, J. E., Rodríguez-Carvajal, M. A., and Vinardell, J. M. 2016. Bacterial molecular signals in the Sinorhizobium fredii-soybean symbiosis. Int. J. Mol. Sci. 17:755.

López-Baena, F. J., Vinardell, J. M., Pérez-Montaño, F., Crespo-Rivas, J. C., Bellogín, R. A., Espuny, M. D. R., and Ollero, F. J. 2008. Regulation and symbiotic significance of nodulation outer proteins secretion in Sinorhizobium fredii HH103. Microbiol. Read. 154:1825-1836.

Lu, D., Lin, W., Gao, X., Wu, S., Cheng, C., Avila, J., Heese, A., Devarenne, T. P., He, P., and Shan, L. 2011. Direct ubiquitination of pattern recognition receptor FLS2 attenuates plant innate immunity. Science 332:1439-1442.

Marie, C., Deakin, W. J., Viprey, V., Kopciñska, J., Golinowski, W., Krishnan, H. B., Perret, X., and Broughton, W. J. 2003. Characterization of Nops, nodulation outer proteins, secreted via the type III secretion system of NGR234. Mol. Plant-Microbe Interact. 16:743-751.

Minamino, N., and Ueda, T. 2019. RAB GTPases and their effectors in plant endosomal transport. Curr. Opin. Plant Biol. 52:61-68.

Miwa, H., and Okazaki, S. 2017. How effectors promote beneficial interactions. Curr. Opin. Plant Biol. 38:148-154.

Muñoz, J. A., Coronado, C., Pérez-Hormaeche, J., Kondorosi, A., Ratet, P., and Palomares, A. J. 1998. MsPG3, a Medicago sativa polygalacturonase gene expressed during the alfalfa-Rhizobium meliloti interaction. Proc. Natl. Acad. Sci. U.S.A. 95:9687-9692.

Qiu, L., Zhang, X., Cheng, J., and Yin, X. 2010. Effects of black locust (Robinia pseudoacacia) on soil properties in the loessial gully region of the Loess Plateau, China. Plant Soil 332:207-217.

Ramírez-Peinado, S., Ignashkova, T. I., van Raam, B. J., Baumann, J., Sennott, E. L., Gendarme, M., Lindemann, R. K., Starnbach, M. N., and Reiling, J. H. 2017. TRAPPC13 modulates autophagy and the response to Golgi stress. J. Cell Sci. 130:2251-2265.

Ravikumar, R., Kalbfuß, N., Gendre, D., Steiner, A., Altmann, M., Altmann, S., Rybak, K., Edelmann, H., Stephan, F., Lampe, M., Facher, E., Wanner, G., Falter-Braun, P., Bhalerao, R. P., and Assaad, F. F. 2018. Independent yet overlapping pathways ensure the robustness and responsiveness of trans-Golgi network functions in Arabidopsis. Development 145:dev169201.

Rehman, R. U., and Di Sansebastiano, G.-P. 2014. Plant Rab GTPases in membrane trafficking and signalling. Pages 51-73 in: Plant Signaling: Understanding the Molecular Crosstalk. Springer, New Delhi, India.

Robert-Seilaniantz, A., Grant, M., and Jones, J. D. 2011. Hormone crosstalk in plant disease and defense: More than just jasmonate-salicylate antagonism. Annu. Rev. Phytopathol. 49:317-343.

Rybak, K., Steiner, A., Synek, L., Klaeger, S., Kulich, I., Facher, E., Wanner, G., Kuster, B., Zarsky, V., Persson, S., and Assaad, F. F. 2014. Plant cytokinesis is orchestrated by the sequential action of the TRAPPII and exocyst tethering complexes. Dev. Cell 29:607-620.

Sacher, M., Shahrzad, N., Kamel, H., and Milev, M. P. 2019. TRAPPopathies: An emerging set of disorders linked to variations in the genes encoding transport protein particle (TRAPP)-associated proteins. Traffic 20:5-26.

Sánchez, C., Iannino, F., Deakin, W. J., Ugalde, R. A., and Lepek, V. C. 2009. Characterization of the Mesorhizobium loti MAFF303099 type-three protein secretion system. Mol. Plant-Microbe Interact. 22:519-528.

Scheidemann, P., and Wetzel, A. 1997. Identification and characterization of flavonoids in the root exudate of Robinia pseudoacacia. Trees (Berl.) 11:316-321.

Skorpil, P., Saad, M. M., Boukli, N. M., Kobayashi, H., Ares-Orpel, F., Broughton, W. J., and Deakin, W. J. 2005. NopP, a phosphorylated effector of Rhizobium sp. strain NGR234, is a major determinant of nodulation of the tropical legumes Flemingia congesta and Tephrosia vogelii. Mol. Microbiol. 57:1304-1317.

Speth, E. B., Imboden, L., Hauck, P., and He, S. Y. 2009. Subcellular localization and functional analysis of the Arabidopsis GTPase RabE. Plant Physiol. 149:1824-1837.

Tokarev, A. A., Taussig, D., Sundaram, G., Lipatova, Z., Liang, Y., Mulholland, J. W., and Segev, N. 2009. TRAPP II complex assembly requires Trs33 or Trs65. Traffic 10:1831-1844.

van Spronsen, P. C., Bakhuizen, R., van Brussel, A. A., and Kijne, J. W. 1994. Cell wall degradation during infection thread formation by the root nodule bacterium Rhizobium leguminosarum is a two-step process. Eur. J. Cell Biol. 64:88-94.

Veitch, N. C., Elliott, P. C., Kite, G. C., and Lewis, G. P. 2010. Flavonoid glycosides of the black locust tree, Robinia pseudoacacia (Leguminosae). Phytochemistry 71:479-486.

Verhoef, L. G., and Wade, M. 2017. Visualization of protein interactions in living cells using bimolecular luminescence complementation (BiLC). Curr. Protocols Protein Sci. 90:30.35.1-30.35.14. 
Wagner, S. C. 2011. Biological nitrogen fixation. Nature Education Knowledge 3:15.

Wang, X., Huo, H., Luo, Y., Liu, D., Zhao, L., Zong, L., Chou, M., Chen, J., and Wei, G. 2019. Type III secretion systems impact Mesorhizobium amorphae CCNWGS0123 compatibility with Robinia pseudoacacia. Tree Physiol. 39:1533-1550.

Wang, X., Weng, M., Ke, Y., Sapp, E., DiFiglia, M., and Li, X. 2020. Kalirin interacts with TRAPP and regulates Rab11 and endosomal recycling. Cells 9:1132.

Xiang, T., Zong, N., Zou, Y., Wu, Y., Zhang, J., Xing, W., Li, Y., Tang, X., Zhu, L., Chai, J., and Zhou, J. M. 2008. Pseudomonas syringae effector AvrPto blocks innate immunity by targeting receptor kinases. Curr. Biol. 18:74-80.

Xie, F., Murray, J. D., Kim, J., Heckmann, A. B., Edwards, A., Oldroyd, G. E., and Downie, J. A. 2012. Legume pectate lyase required for root infection by rhizobia. Proc. Natl. Acad. Sci. U.S.A. 109:633-638.

Wong, E. Y. M., Tse, J. Y. M., Yao, K.-M., Tam, P.-C., and Yeung, W. S. B. 2002. VCY2 protein interacts with the HECT domain of ubiquitin-protein ligase E3A. Biochem. Biophys. Res. Comm. 296:1104-1111.

Young, M. D., Wakefield, M. J., Smyth, G. K., and Oshlack, A. 2010. Method gene ontology analysis for RNA-seq accounting. Genome Biol. 11:R14.
Yu, S., and Liang, Y. 2012. A trapper keeper for TRAPP, its structures and functions. Cell. Mol. Life Sci. 69:3933-3944.

Yuksel, B., and Memon, A. R. 2008. Comparative phylogenetic analysis of small GTP-binding genes of model legume plants and assessment of their roles in root nodules. J. Exp. Bot. 59:3831-3844.

Zahran, H. H. 1999. Rhizobium-legume symbiosis and nitrogen fixation under severe conditions and in an arid climate. Microbiol. Mol. Biol. Rev. 63:968-989.

Zhang, B., Wang, M., Sun, Y., Zhao, P., Liu, C., Qing, K., Hu, X., Zhong, Z., Cheng, J., Wang, H., Peng, Y., Shi, J., Zhuang, L., Du, S., He, M., Wu, H., Liu, M., Chen, S., Wang, H., Chen, X., Fan, W., Tian, K., Wang, Y., Chen, Q., Wang, S., Dong, F., Yang, C., Zhang, M., Song, Q., Li, Y., and Wang, X. 2021. Glycine max NNL1 restricts symbiotic compatibility with widely distributed bradyrhizobia via root hair infection. Nat. Plants 7:73-86.

Zhang, J., Chen, J., Wang, L., Zhao, S., Li, J., Liu, B., Li, H., Qi, X., Zheng, H., and Lu, M. 2018. AtBET5 is essential for exine pattern formation and apical meristem organization in Arabidopsis. Plant Sci. 274:231-241.

Zou, H., Zhang, N.-N., Lin, X.-Y., Zhang, W.-Q., Zhang, J.-H., Chen, J., and Wei, G.-H. 2020. Hydrogen sulfide is a crucial element of the antioxidant defense system in Glycine max-Sinorhizobium fredii symbiotic root nodules. Plant Soil 449:209-231. 